\title{
Psycho-social profile of school going children involved in any form of bullying
}

\author{
Sumanth Ediga Kornapalli ${ }^{1}$, Raghuram Macharapu ${ }^{2, *}$, Pramod KR Mallepalli ${ }^{3}$, Ravulapati Sateesh Babu ${ }^{4}$ \\ ${ }^{1}$ Post Graduate, ${ }^{2}$ Associate Professor, ${ }^{3}$ Professor and HOD, ${ }^{4}$ Professor, Dept. of Psychiatry, Mamata Medical College, Khammam, \\ Telangana, India
}

*Corresponding Author: Raghuram Macharapu

Email: raghuram.macharapu@gmail.com

\begin{abstract}
Introduction: Bullying is intentional, repeated negative behavior by one or more persons directed against a person who can't defend $\mathrm{him} /$ herself. Over all prevalence of bullying in Indian schools in previous studies is $53 \%$.

Bullying is major problem in both adolescents and children. With advent of increased aggression and violence in schools studying bullying and its effects is necessary especially in the Indian context where there is paucity of literature.

Aims and Objectives: The present study is an attempt to assess prevalence of bullying, identifying bullies and victims and to study the psycho-social profile of school going children involved in any form of bullying.

Materials and Methods: The total sample comprised of 249 students studying in the 5 th and $6^{\text {th }}$ class. They were administered the Peer Interaction in Primary School Questionnaire (PIPS), Strengths and Difficulties Questionnaire (SDQ) and details like weight, height and academic performance were also collected.

Results: In the current study boys were more predominant in the bullies group. Verbal bullying (teasing and making fun) was more frequent compared to physical forms. Bully victim groups significantly had more emotional symptoms, peer problems and hyperactivity compared to other groups. Bully group had more conduct problems compared to other groups.
\end{abstract}

Keywords: Bullies, Victims, Bully-victims, Psychosocial profile.

\section{Introduction}

Bullying is a widespread predicament among children and adolescents. ${ }^{1-4}$ According to Olweus, ${ }^{1}$ "A person is bullied when he or she is exposed, repeatedly and over a period of time, to negative actions on the part of one or more other persons, and he or she has difficulty defending himself or herself". This definition identifies three major components of bullying: Firstly, it is an aggressive behavior which involves unwanted, negative actions. Secondly, bullying usually involves a pattern of identifiable behaviors which are repeated over time. Finally, it involves a difference in imbalance of power between the bully and the victim.

In previous studies conducted in Indian schools, the prevalence of any form of bullying involvement was about $53 \%{ }^{5-7}$ Bullying consists of three main types of participants: bullies, victims, and bully-victims.

Bullied victims experience anxiety, depression, poor academic performance, and psychosomatic complaints, such as headaches and abdominal pain, especially in the morning as short-term consequences. Long-term consequences include lower self-esteem, poor academic achievement, and poor psychosocial adjustment as adults. ${ }^{8-11}$ Bullying is significantly associated with suicidal ideation and suicide attempts. ${ }^{12,13}$

Some children play the role of perpetrators while others play the role of victims, however there are some that play the role of both perpetrators and victims. Such children with a dual role are called bully-victims. Bully-victims suffer from both behavioral and emotional problems. ${ }^{14}$ They are at a greater risk of suffering the adverse effects. ${ }^{15-18}$ By nature, bullying is a vicious cycle, therefore bullying may be the cause and/or the aftermath of emotional and behavioral problems, thus the need to treat both the bully and the victim is manifest, but most of the anti-bullying programs fail to do so.

Very limited information is available about bullying and its psychosocial profile in context of Indian literature. Current study concentrates on these factors to acquire adequate information which may contribute to effective devising of bullying prevention programs.

\section{Aims and Objectives}

1. To study psychosocial profile of the school going children who are involved in any form of bullying.

2. To study the gender difference in involvement in any form of bullying.

3. To study the association between involvement in bullying and psychosocial variables.

\section{Materials and Methods}

It was a cross sectional study done form August 2017 to December 2017 in Two local private schools from Khammam. A total of 249 students studying in the 5 th and $6^{\text {th }}$ class were taken up for the study. Students who gave accent for the study and whose parents were willing to give written informed consent were included in the study.

Convenient sampling technique was used and the available English medium schools which had given permission for conducting the study were included in the present study. Ethical clearance was obtained from Institutional Review Board. Consent was taken from the parents of students after writing a letter explaining the study to them an students assent was taken.

Students were asked to fill semi structured socio demographic proforma which contained parameters like age, sex and number of friends. Information about weight, height was recorded manually by the researcher. Body Mass Index 
was calculated from the information available and noted. Academic performance was measured by the percentage of marks obtained in the last exam. Students were asked to fill the percentage of marks and later it was confirmed by the class teacher. Self-report questionnaires namely peer interaction in Primary Schools Questionnaire (PIPS) and Strengths and Difficulties Questionnaire (SDQ) were filled by the students.

Strengths and Difficulties Questionnaire (SDQ): ${ }^{19}$ This is a self-administered, English version of SDQ that has 25 items with 5 subscales. The scale is used to analyze the psychosocial effects i.e., the emotional, behavioral and interpersonal problems caused by bullying. SDQ-25 is administered as self -report among children above $11 \mathrm{yrs}$ but a study conducted proved validation of self-report for age of 6-10yrs. ${ }^{20}$

Peer interaction in Primary Schools Questionnaire (PIPS): ${ }^{21}$ it is a self-administered scale consisting of 22 items scored on a three-point scale: "never", "sometimes" and "a lot". It has two sub-scales, Victim and bully. The subscale points to which is more predominant, bully perpetration or victimhood. PIPS has been designed for use in primary schools; however, the behaviors listed were equally relevant in current context. Higher score of PIPS bully scale indicates more bully perpetration and higher score on victim scale indicates more victimization.

Categorization of Bullying Behaviors: Bullying behaviors were the dependent variables. We used the following definition: "Bullying is when another student, or group of students, says or does nasty and unpleasant things to him or her. It is also bullying when a student is teased repeatedly in a way he or she doesn't like. But it is not bullying when two students about the same strength quarrel or fight. ${ }^{22}$ Segregation into victim, bully and bully-victim was done based on two SDQ questions viz. "Other people or young children pick on me or bully me" and "I fight a lot. I can make other people do what I want

\section{Statistical Analysis}

Statistical analysis was done by Statistical package of social sciences for windows version SPSS-20. As the data is non-parametric to calculate the $\mathrm{P}$ value Mann Whitney $\mathrm{U}$ test is done for two independent variables and Kruskal Wallis test if more than 2 independent variables are present. Pearson's correlation is done to check correlation between two variables.

\section{Results}

The total number of students taken up for the study were 249 of which $41 \%$ were involved in bullying in one form or the other. The victims were $27 \%$, bullies $5 \%$ and the bully victims $9 \%$.( Table 1 )

Comparing the genders it was found that males were significantly more likely to be perpetrators of bullying. (Table 2)

Table 1: Sample distribution in current study

\begin{tabular}{|l|c|}
\hline Total number of students participated in the study & 249 \\
\hline Total students involved in bullying & $102(40.9 \%)$ \\
\hline Victims (V) & $67(26.9 \%)$ \\
\hline Bullies + Victims (B+V) & $23(9.2 \%)$ \\
\hline Bullies & $12(4.8 \%)$ \\
\hline Neither bullying nor victims & $147(59.03 \%)$ \\
\hline
\end{tabular}

Table 2: Bully perpetration and victimization between males and females

\begin{tabular}{|l|c|c|c|}
\hline & Males $(\mathbf{N}=139)$ & Females $\mathbf{( N = 1 1 0 )}$ & P value \\
\hline PIPS Victim Subscale & $7.62 \pm 4.49$ & $5.29 \pm 3.37$ & 0.7532 \\
\hline PIPS Bully subscale & $7.79 \pm 4.02$ & $4.41 \pm 2.74$ & $0.0027^{*}$ \\
\hline
\end{tabular}

$*$ p value $<0.05$

Students with less number of friends are more likely to be bully perpetrators and victims and the scores on PIPS bully scale and PIPS victim scale are significantly higher in students with less number of friend.(Table 3). Among students of three different BMI levels underweight, normal weight and overweight scores on PIPS victim scale and PIPS bully scale are higher with increase in Body mass index. But significance is present only in PIPS victim scale. Therefore, over weight individuals are more likely to be victimized. (Table 4). There was no significant relationship of academic performance with relation to bully perpetration and victimization in students.

Table 3: Bully perpetration and victimization among students who have $\leq 7$ friends and $>7$ friends

\begin{tabular}{|l|c|c|c|}
\hline & $<\mathbf{7}(\mathbf{n}=\mathbf{5 0})$ & $>\mathbf{7}(\mathbf{n}=\mathbf{1 9 9})$ & P value \\
\hline PIPS Victim & $9.4 \pm 4.10$ & $7.26 \pm 4.225$ & $0.001^{*}$ \\
\hline PIPS Bully & $6.14 \pm 3.35$ & $4.58 \pm 3.006$ & $0.002^{*}$ \\
\hline
\end{tabular}

$*$ p value $<0.05$ 
Table 4: Bully perpetration and victimization in students of three various BMI levels

\begin{tabular}{|l|c|c|c|c|}
\hline & $\begin{array}{c}\text { Under weight } \\
(\mathbf{N = 1 7 9 )} \mathbf{7 1 . 8 8 \%}\end{array}$ & $\begin{array}{c}\text { Normal weight } \\
(\mathbf{N = 5 6 ) ~ 2 2 . 4 8 \%}\end{array}$ & $\begin{array}{c}\text { Over weight } \\
(\mathbf{N = 1 4 )} \mathbf{5 . 6 2 \%}\end{array}$ & P value \\
\hline PIPS Victim scale & $7.3 \pm 4.09$ & $8.16 \pm 4.38$ & $10.78 \pm 5.07$ & $0.018^{*}$ \\
\hline PIPS Bully scale & $4.79 \pm 2.99$ & $5.01 \pm 3.59$ & $5.71 \pm 3.04$ & 0.583 \\
\hline
\end{tabular}

*p value $<0.05$

Students who belongs to victims group based on SDQ have scored significantly higher on PIPS victim scale compared to non-victims. Students who belongs to bullies group based on SDQ scored significantly higher on PIPS bully scale compared to non-bullies. (Table 5). There is significant positive correlation between total difficulties score of strengths and difficulties questionnaire and the victim, bully subscale scores on Peer interaction in primary school questionnaire respectively. Students with more difficulties are likely to be bully perpetrators and victims (Table 6).

However no significant correlation was present in pro social scale between bully perpetration and victimization scores.

Table 5: Bully perpetration and victimization in the groups divided based on strengths and difficulties questionnaire

\begin{tabular}{|l|c|c|c|}
\hline & Victims on SDQ $(\mathbf{n = 9 0})$ & $\begin{array}{c}\text { Non-victims on SDQ } \\
(\mathbf{n}=\mathbf{1 5 9})\end{array}$ & $\mathbf{p}$ value \\
\hline PIPS victim scale & $11.14 \pm 3.488$ & $5.74 \pm 3.35$ & $<0.001$ \\
\hline & Bullies $(\mathrm{n}=35)$ & Non-bullies $(\mathrm{n}=214)$ & $\mathrm{p}$ value \\
\hline PIPS bully scale & 9.485 & 4.14 & $<0.00001$ \\
\hline
\end{tabular}

*p value $<0.05$

Table 6: Bully perpetration and victimization in correlation with total difficulties score on Strengths and difficulties questionnaire

\begin{tabular}{|c|c|c|}
\hline & $\begin{array}{c}\text { PIPS victim scale } \\
(7.694 \pm 4.27)\end{array}$ & $\begin{array}{c}\text { PIPS bully scale } \\
(4.899 \pm 3.134)\end{array}$ \\
\hline $\begin{array}{l}\text { Total difficulties Score } \\
(14.96 \pm 4.775)\end{array}$ & $\begin{array}{l}\mathrm{R}=0.479 \\
\mathrm{P}<0.001\end{array}$ & $\begin{array}{l}\mathrm{R}=0.460 \\
\mathrm{P}<0.001\end{array}$ \\
\hline
\end{tabular}

*p value $<0.05$

Bully victim groups have significantly more emotional symptoms, peer problem and hyperactivity compared to other groups. Bully group have more conduct problems significantly compared to other groups. There was significantly no difference in pro social scores between four groups. (Table 7).

Table 7: Comparison of 5 sub scales of strengths and difficulties questionnaire between 4 groups divided based on involvement in bullying

\begin{tabular}{|l|c|c|c|c|c|}
\hline & $\begin{array}{c}\mathbf{V}(\mathbf{n}=\mathbf{6 7}) \\
\mathbf{2 9 . 9 \%}\end{array}$ & $\begin{array}{c}\mathbf{B + V}(\mathbf{n = 2 3}) \\
\mathbf{9 . 2 \%}\end{array}$ & $\mathbf{B}(\mathbf{n = 1 2}) \mathbf{4 . 8 \%}$ & $\begin{array}{c}\mathbf{N}(\mathbf{n = 1 4 7}) \\
\mathbf{5 9 . 1 \%}\end{array}$ & P value \\
\hline Emotional symptom & 4.65 & 5 & 3.91 & 3.1632 & 0.002 \\
\hline Conduct problem & 3.253 & 5.608 & 6.25 & 2.734 & 0.0001 \\
\hline Hyperactivity & 3.70 & 4.956 & 4.083 & 3.054 & 0.0022 \\
\hline Peer problem & 5.626 & 6.217 & 4.916 & 3.639 & 0.05 \\
\hline Prosocial scale & 7.582 & 7.65 & 6.333 & 7.517 & 0.2433 \\
\hline
\end{tabular}

$* p$ value $<0.05$

Being made fun of (P19=0.79) and sad by others (P17=0.76) are frequently experienced behaviors of victims. Being mean to other students $(\mathrm{P} 14=0.83)$ and saying mean things about a student to make other kids laugh $(\mathrm{P} 8=0.642)$ are frequently experienced behaviors of bullies. Male children tend to push or slap other students (P4) more often compared to female children. Females tend to feel that other students look at them in a mean way (P5) more often compared to males. Male children tend to call other students bad names (P12) more often compared to female children. In current study sample the mean score of P1 in the PIPS questionnaire, (whether other students make me cry) is 0.618 and there is no significant gender difference present for this question. When mean score of P2 (whether I tease others) of current study sample is calculated total score is 0.497 and there is no significant gender difference present for this question. (Table 8) 
Table 8: Showing mean and SD of each item on PIPS scale and its gender difference

\begin{tabular}{|l|c|c|c|c|c|c|c|}
\hline & \multicolumn{2}{|c|}{ Total } & \multicolumn{2}{c|}{ Male } & \multicolumn{2}{c|}{ Female } & p value \\
\hline P1 & 0.618 & 0.556 & 0.60 & 0.559 & 0.647 & 0.554 & 0.674 \\
\hline P2 & 0.497 & 0.582 & 0.561 & 0.591 & 0.427 & 0.564 & 0.080 \\
\hline P4 & 0.409 & 0.582 & 0.5107 & 0.618 & 0.289 & 0.509 & $0.008^{*}$ \\
\hline P5 & 0.57 & 0.618 & 0.503 & 0.641 & 0.656 & 0.581 & $0.04^{*}$ \\
\hline P8 & 0.642 & 0.704 & 0.625 & 0.683 & 0.658 & 0.732 & 0.802 \\
\hline P12 & 0.405 & 0.575 & 0.489 & 0.606 & 0.307 & 0.516 & $0.009^{*}$ \\
\hline P14 & 0.835 & 0.803 & 0.848 & 0.833 & 0.832 & 0.768 & 0.865 \\
\hline P17 & 0.767 & 0.685 & 0.769 & 0.715 & 0.767 & 0.648 & 0.936 \\
\hline P19 & 0.799 & 0.718 & 0.791 & 0.736 & 0.813 & 0.697 & 0.794 \\
\hline
\end{tabular}

\section{Discussion}

Over all prevalence of students who are participants of any form of bullying is $40.9 \%(\mathrm{n}=102)$ which comprised of $26.9 \%$ victims $(n=67), 9.2 \%(n=23)$ bully-victims and $4.8 \%$ bullies $(n=12)$ respectively. The prevalence in current study is in concordance with a Korean study where $40 \%$ students surveyed played some role in bullying with at least $23 \%$ being victims or victim-perpetrators. ${ }^{13}$ Prevalence of Bullying-related involvement in our study is comparable to recent Indian studies ${ }^{6,7}$ though it is much higher compared to western literature. ${ }^{23}$

In our study, boys are predominant in bullies-group. Previous research showed that boys are more likely to be bullies and girls are more likely to be victims. ${ }^{5,24}$

Among students of three different BMI levels underweight, normal weight and overweight scores on PIPS victim scale and PIPS bully scale are higher with increase in Body mass index. But significance is present only in PIPS victim scale. Therefore, overweight individuals are more likely to be victimized these results are similar to study conducted by H.A. Patel and coworkers. ${ }^{25}$ Students with less number of friends are more likely to be bully perpetrators and victims and the scores on PIPS bully scale and PIPS victim scale are significantly higher in students with less number of friends. This may be due to poor psychosocial adjustment of students involved in any form of bullying similar to previous study conducted by H.A. Patel and coworkers. ${ }^{25}$

There was no significance of academic performance with relation to bully perpetration and victimization in students. Mean scores on each item of PIPS scale is calculated to point the most common bullying behavior is verbal bullying (teasing and making fun) with physical forms not being infrequent, which is similar to earlier studies..$^{5-7}$

According to current study Bully victim groups have significantly more emotional symptoms, peer problem and hyperactivity compared to other groups. Bully group have conduct problems significantly more compared to other groups. These results of psychosocial profile are similar to previous studies conducted in emotional and behavioral perspective where victims experience emotional problems, bullies experience behavioral problems, and bully-victims experience both emotional and behavioral problems. ${ }^{15}$ The bully-victims generally experience the most problems and have the highest risk of adverse outcomes according to previous studies. ${ }^{16-18}$

\section{Conclusion}

In current study boys are more likely to be bullies than girls as bullying is based on power differential. This finding is in accordance with previous studies. Psychosocial profile in current study shows that bully victims are more likely to have both emotional and behavioral problems while bullies have behavioral problems.

\section{Limitations of the Study}

This study has a few limitations. It used self-reported measures rather than incorporating parent and teacher reporting. Besides, SDQ is only a screening tool and therefore future research in this area needs to use more detailed assessment tools for the complete picture of emotional and behavioral problems to emerge.

Small sample size, use of convenient sampling and narrow age range are some of the other limitations of the present study Inclusion of only English medium schools and not measuring cyberbullying are also limitations of current study. Although it is not certain whether bullying is a cause or an effect of the emotional and behavioral problems experienced by children, an association between bullying behavior and such problems seems likely; in which case those involved in bullying, whether they are victims or perpetrators, may require comprehensive treatment to solve their emotional and behavioral problems and improve their outcomes in relation to bullying prevention programs. Further, link between computer gaming involving virtual violence and bullying behavior to be assessed in future studies.

\section{Acknowledgement: Nil.}

\section{Conflict of Interest: Nil.}

\section{References}

1. Olweus D. Bullying at School: What We Know and What We Can Do. Oxford, England: Blackwell Publishing; 1993.

2. Salmivalli C, Lagerspetz K, Bjorkqvist K, Osterman K, Kaukiainen A. Bullying as a group process: Participant roles and their relations to social status within the group. Aggress Behav. 1996;22:1-15. 
3. Smith PK, Pepler D, Rigby K. Bullying in schools: How successful can interventions be? Cambridge, UK: Cambridge University Press; 2004.

4. Menesini E. School bullying in Italy. Nature, functions from childhood to adolescence and related interventions. In Understanding and addressing bullying: An international perspective, Volume 1. Edited by Pepler D, Craig W. Bloomington, Indian a: Author House; 2008:253-270.

5. Kshirsagar VY, Agarwal R, Bavdekar SB. Bullying in schools: prevalence and short-term impact. Indian Pediatrics. 2007;44(1):25.

6. Ramya SG, Kulkarni ML. Bullying among school children: prevalence and association with common symptoms in childhood. Indian J Pediatr. 2011;78(3):307-310.

7. Malhi P, Bharti B, Sidhu M. Aggression in schools: psychosocial outcomes of bullying among Indian adolescents. Indian J Pediatr. 2014;81(11):1171-1176.

8. Anderson M, Kaufman J, Simon TR, Barrios L, Paulozzi L, Ryan G, Hammond R, Modzeleski W, Feucht T, Potter L, School-Associated Violent Deaths Study Group. Schoolassociated violent deaths in the United States, 1994-1999. Jama. 2001;286(21):2695-2702.

9. Rigby K. Consequences of bullying in schools. Can J Psychiatry. 2003;48(9):583-590.

10. Salmon G, West A. Physical and mental health issues related to bullying in schools. Current Opinion in Psychiatry. 2000;13(4):375-380.

11. Spector ND, Kelly SF. Pediatrician's role in screening and treatment: bullying, prediabetes, oral health. Curr Opin Pediatr. 2006;18(6):661-670.

12. Hinduja S, Patchin JW. Bullying, cyberbullying, and suicide. Arch Suicide Res. 2010;14(3):206-221.

13. Kim YS, Koh YJ, Leventhal BL. Prevalence of school bullying in Korean middle school students. Arch Pediatr Adolesc Med. 2004;158(8):737-741

14. Ayers SL, Wagaman MA, Geiger JM, Bermudez-Parsai M, Hedberg EC. Examining school-based bullying interventions using multilevel discrete time hazard modeling. Prev Sci. 2012;13(5):539-550.

15. 15Elgar FJ, Pickett KE, Pickett W, Craig W, Molcho M, Hurrelmann K, Lenzi M. School bullying, homicide and income inequality: a cross-national pooled time series analysis. Int J Public Health. 2013;58(2):237-245.
16. Shakoor S, Jaffee SR, Bowes L, Ouellet-Morin I, Andreou P, Happé F, Moffitt TE, Arseneault L. A prospective longitudinal study of children's theory of mind and adolescent involvement in bullying. J Child Psychol Psychiatry. 2012;53(3):254-261.

17. Albores-Gallo L, Sauceda-García JM, Ruiz-Velasco S, RoqueSantiago E. Bullying and its association with psychiatric disorders in a Mexican students sample. Salud publica de Mexico. 2011;53(3):220-227.

18. Meland E, Rydning JH, Lobben S, Breidablik HJ, Ekeland TJ. Emotional, self-conceptual, and relational characteristics of bullies and the bullied. Scand J Public Health. 2010;38(4):359367.

19. Goodman R. The Strengths and Difficulties Questionnaire: a research note. J Child Psychol Psychiatry. 1997;38(5):581586.

20. Curvis W, McNulty S, Qualter P. The validation of the selfreport Strengths and Difficulties Questionnaire for use by 6-to 10-year-old children in the UK. Br J Clin Psychol. 2014;53(1):131-137.

21. Tarshis TP, Huffman LC. Psychometric properties of the Peer Interactions in Primary School (PIPS) questionnaire. J Dev Behav Pediatr. 2007;28(2):125-132.

22. Bauman A, Hogan A, McLellan L, Rissel C, Mayne D, Gill L. Health behaviours of New South Wales school students: report of the NSW health behaviour of school students (NSW HBSS) survey, 1996. Sydney, NSW: National Centre for Health Promotion. 1998.

23. Craig W, Harel-Fisch Y, Fogel-Grinvald H, Dostaler S, Hetland J, Simons-Morton B, Molcho M, de Mato MG, Overpeck M, Due P, Pickett W. A cross-national profile of bullying and victimization among adolescents in 40 countries. Int J Public Health. 2009;54(2):216-224.

24. Hymel S, Swearer SM. Four decades of research on school bullying: An introduction. Am Psychologist. 2015;70(4):293.

25. Patel HA, Varma J, Shah S, Phatak A, Nimbalkar SM. Profile of bullies and victims among urban school-going adolescents in Gujarat. Indian Pediatr. 2017;54(10):841-843. 